\title{
Gibberellin in tomato: metabolism, signaling and role in drought responses
}

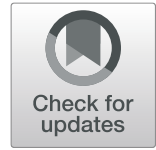

Hagai Shohat ${ }^{1}$, Natanella Illouz Eliaz ${ }^{2}$ and David Weiss ${ }^{1 *}$ (D)

\begin{abstract}
The growth-promoting hormone gibberellin (GA) regulates numerous developmental processes throughout the plant life cycle. It also affects plant response to biotic and abiotic stresses. GA metabolism and signaling in tomato (Solanum lycopersicum) have been studied in the last three decades and major components of the pathways were characterized. These include major biosynthesis and catabolism enzymes and signaling components, such as the three GA receptors GIBBERELLIN INSENSITIVE DWARF 1 (GID1) and DELLA protein PROCERA (PRO), the central response suppressor. The role of these components in tomato plant development and response to the environment have been investigated. Cultivated tomato, similar to many other crop plants, are susceptible to water deficiency. Numerous studies on tomato response to drought have been conducted, including the possible role of GA in tomato drought resistance. Most studies showed that reduced levels or activity of GA improves drought tolerance and drought avoidance. This review aims to provide an overview on GA biosynthesis and signaling in tomato, how drought affects these pathways and how changes in GA activity affect tomato plant response to water deficiency. It also presents the potential of using the GA pathway to generate drought-tolerant tomato plants with improved performance under both irrigation and water-limited conditions.
\end{abstract}

Keywords: Gibberellin, DELLA, Abscisic acid, Drought resistance, Tomato, Gene editing, Yield

\section{Introduction}

Drought is a common and devastating abiotic stress which causes damage to crops worldwide (Dai, 2011; Tardieu, 2020). Water deficiency directly and indirectly suppresses major biochemical pathways, including photosynthesis and primary carbon metabolism, leading to inhibition of growth, flowering and fruit development (Zhu, 2016; Tardieu et al., 2018). Plants have adopted three major strategies to cope with drought: drought escape, drought tolerance and drought avoidance (Chaves et al., 2003). Some annual plants escape from severe drought by early flowering (Kooyers, 2015). Drought tolerance is acquired by osmotic adjustment (accumulation of osmolytes), accumulation of stress-

\footnotetext{
* Correspondence: david.weiss@mail.huji.ac.il

1 Institute of Plant Sciences and Genetics in Agriculture, The Hebrew University of Jerusalem, P.O. Box 12, 76100 Rehovot, Israel

Full list of author information is available at the end of the article
}

protecting proteins and scavenging of reactive oxygen species (ROS) (Vinocur and Altman, 2005). All higher (vascular) plants exhibit 'drought avoidance' (droughtstress avoidance) responses during transient waterdeficit episode. These include rapid stomatal closure and suppression of canopy growth to reduce transpiration (Brunner et al., 2015; Lind et al., 2015). At the same time, roots continue to grow, in search of new sources of water, a phenomenon called hydro- or xero-tropism (Feng et al., 2016; Dietrich, 2018). This leads to an increased root-to-shoot ratio and improved water balance.

Phytohormones play a central role in plant responses to drought (Verma et al., 2016; Gupta et al., 2020). During the early stages of soil dehydration, the major stress hormone abscisic acid (ABA) accumulates and induces various drought responses (Cutler et al., 2010), leading, in some plants, to drought tolerance, and in all higher plants to 'drought avoidance' (Kooyers, 2015). Numerous

(c) The Author(s). 2021 Open Access This article is licensed under a Creative Commons Attribution 4.0 International License, which permits use, sharing, adaptation, distribution and reproduction in any medium or format, as long as you give appropriate credit to the original author(s) and the source, provide a link to the Creative Commons licence, and indicate if changes were made. The images or other third party material in this article are included in the article's Creative Commons licence, unless indicated otherwise in a credit line to the material. If material is not included in the article's Creative Commons licence and your intended use is not permitted by statutory regulation or exceeds the permitted use, you will need to obtain permission directly from the copyright holder. To view a copy of this licence, visit http://creativecommons.org/licenses/by/4.0/ The Creative Commons Public Domain Dedication waiver (http://creativecommons.org/publicdomain/zero/1.0/) applies to the data made available in this article, unless otherwise stated in a credit line to the data. 
studies have shown that the growth-promoting hormones, auxin (Shani et al., 2017; Salehin et al., 2019), cytokinins (Nishiyama et al., 2011, Nishiyama et al., 2011; Farber et al., 2016), brassinosteroids (Ye et al., 2017; Planas-Riverola et al., 2019; Xie et al., 2019) and gibberellins (GAs, Colebrook et al., 2014), reduce plant resistance to water deficiency.

The growth-promoting hormone GA regulates numerous developmental processes throughout the plant life cycle, from seed germination to fruit development (Yamaguchi, 2008; Daviere and Achard, 2013). GA also negatively affects plant response to biotic and abiotic stresses (Navarro et al., 2008; Colebrook et al., 2014). GA and inhibitors of GA biosynthesis are widely used in agriculture to control germination, stem elongation, plant architecture, flowering time and fruit development (Rademacher, 2016). Accumulating evidence suggest that inhibition of GA activity, either by chemical treatments or by gene-editing, can also be used to improve plant performance under stress conditions (Eshed and Lippman, 2019). Drought opposes GA-induced processes; it inhibits seed germination, shoot growth and fruit development (Munns and Tester, 2008). Several studies have shown that osmotic stress inhibits GA accumulation (Achard et al., 2006; Nelissen et al., 2018; Shohat et al., 2021). In turn, the reduced GA levels lead to the accumulation of DELLA, the master growth inhibitor, which promotes adaptation to abiotic stresses, including drought (Colebrook et al., 2014).

Tomato (Solanum lycopersicum), like many other crops, is susceptible to drought (Iovieno et al., 2016; Zhou et al., 2019). In the past two decades, numerous studies on tomato response to drought have been conducted (Gur and Zamir, 2004; Gong et al., 2010), including studies assessing the role of GA in such processes (Nir et al., 2014, 2017; Omena-Garcia et al., 2019; IllouzEliaz et al., 2020; Shohat et al., 2021). Here, we review the current knowledge on GA biosynthesis and signaling in tomato, how drought affects these pathways and how these changes in hormone activity affect tomato plant response to water deficiency. We also present the potential in exploiting the GA pathway to generate droughttolerant tomato plants with improved performance under irrigation and water-limited conditions.

\section{GA metabolism and signaling GA metabolism}

A comprehensive and up-to-date review on GA metabolism was recently published by Hedden (2020). GAs are diterpenoids, produced from the general substrate geranylgeranyl diphosphate (GGPP), which is converted to ent-kaurene by ent-copalyl diphosphate synthase (CPS) and ent-kaurene synthase (KS) in the plastids (Fig. 1). ent-kaurene is then converted to the first GA precursor
$\mathrm{GA}_{12}$, by two cytochrome P450 monooxygenases, i.e., ent-kaurene oxidase $(\mathrm{KO})$ and ent-kaurenoic acid oxidase (KAO), which act on the outer membrane of the plastids and in the endoplasmic reticulum, respectively. Bioactive GAs, are synthesized in the cytosol from $\mathrm{GA}_{12}$ and $\mathrm{GA}_{53}$ by two 2-oxoglutarate-dependent dioxygenases (2-ODDs) families, GA 20-oxidases (GA20ox) and GA 3-oxidases (GA3ox). $\mathrm{GA}_{12}$ is converted to $\mathrm{GA}_{9}$, and $\mathrm{GA}_{53}$ to $\mathrm{GA}_{20}$, by GA20oxs. Then, GA3oxs, convert $\mathrm{GA}_{20}$ and $\mathrm{GA}_{9}$ by $3 \beta$-hydroxylation to $\mathrm{GA}_{1}$ and to $\mathrm{GA}_{4}$, respectively.

GA deactivation plays a central role in the regulation of bioactive GA accumulation in response to both environmental and developmental cues (Yamaguchi et al., 2008). GA inactivation is primarily catalyzed by another family of 2-ODD enzymes, known as GA 2-oxidases (GA2ox), which reduce the levels of bioactive GAs. GA2ox genes are classified as either class I, which catalyze the conversion of bioactive GAs $\left(\mathrm{GA}_{1}\right.$ and $\left.\mathrm{GA}_{4}\right)$ or their direct precursors $\left(\mathrm{GA}_{20}\right.$ and $\left.\mathrm{GA}_{9}\right)$ to biologically inactive GA derivatives, or class III, which use the early GA precursors $\mathrm{GA}_{12}$ and $\mathrm{GA}_{53}$ as substrates. Other GA deactivation mechanisms are driven by cytochrome P450s, which acts on non-13-hydroxylated GAs $\left(\mathrm{GA}_{12}\right.$, $\mathrm{GA}_{9}$ and $\mathrm{GA}_{4}$ ) to produce epoxidized GAs that lack biological activity (Zhu et al., 2006), and GA METHYL TRANSFERASE1 (GAMT1) enzymes, which methylate bioactive GAs to form inactive GA methyl esters (Varbanova et al., 2007).

\section{$G A$ sensing and signaling}

GA acts by triggering the destruction of DELLA (Locascio et al., 2013). While DELLAs lack a DNA-binding domain, they interact with transcription factors to activate and repress transcription (Zentella et al., 2007; Yoshida et al., 2014). GA binding to the GIBBERELLIN-INSENSITIVE DWARF1 (GID1) receptor increases receptor affinity to DELLA, leading to the formation of the GA-GID1-DELLA complex (Fig. 1). This facilitates the interaction of DELLA with an SCF E3 ubiquitin ligase complex via the GID2/SLEEPY1 (SLY1) F-box protein. The SCF ${ }^{\mathrm{SLY} 1}$ complex polyubiquitinates DELLA, targeting it for degradation by the 26S proteasome (Sasaki et al., 2003; Dill et al., 2004; Griffiths et al., 2006; Harberd et al., 2009; Hauvermale et al., 2012), which subsequently leads to transcriptional reprogramming and activation of GA-dependent responses.

GID1 interacts with DELLA's N-terminal region which harbors the conserved DELLA and VHYNP motifs. The C-terminal region of DELLA interacts with various transcription factors to repress GA responses, rendering it the element responsible for DELLA activity (Sun et al., 2012; Locascio et al., 2013). Mutations in the N-terminal 


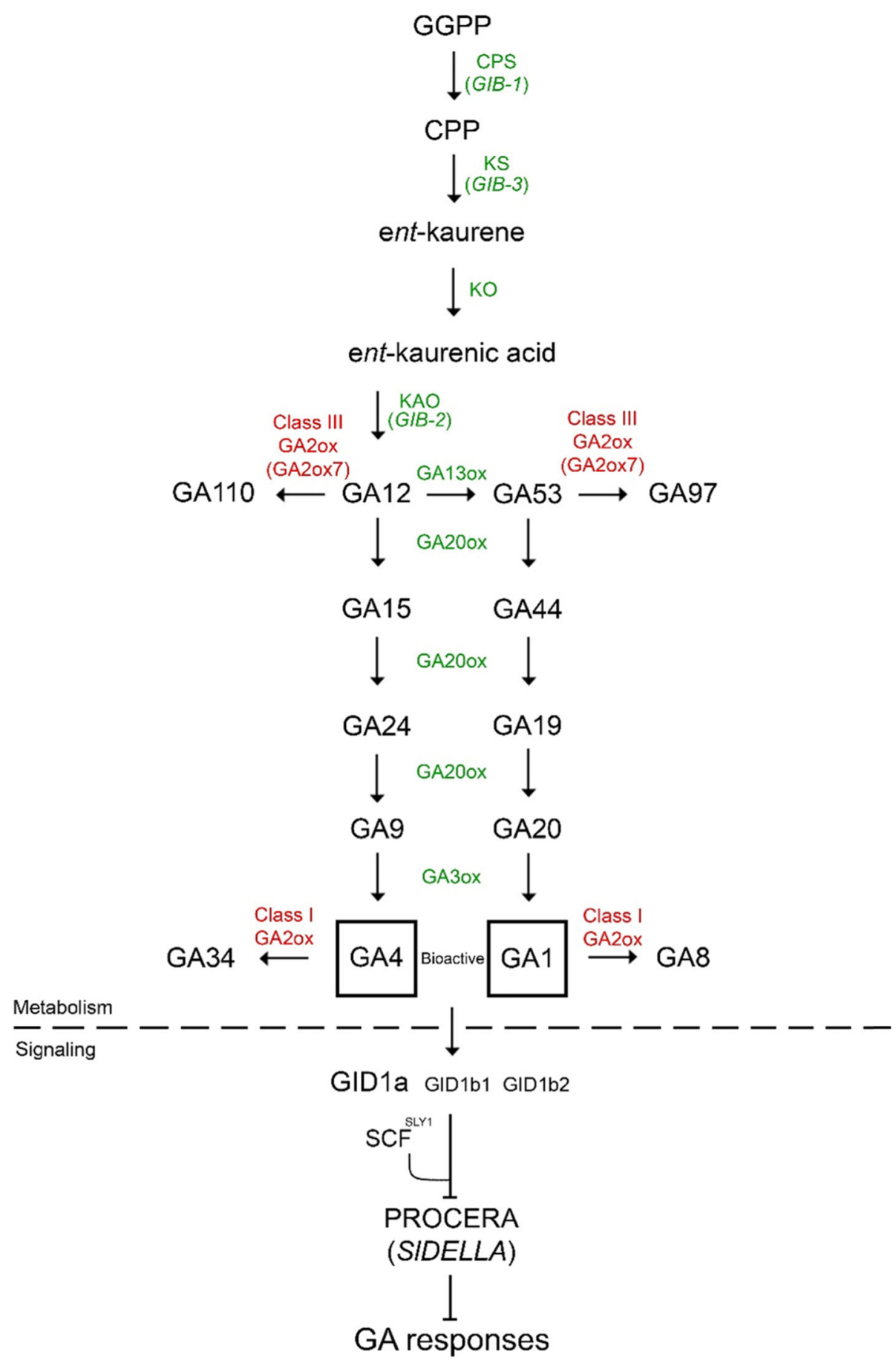

Fig. 1 GA metabolic and signaling pathways in tomato. The scheme shows GA biosynthesis enzymes (green), GA deactivation enzymes (red) and bioactive GAs (black squares)

region of DELLA block its interaction with the GID1 receptor, thereby preventing DELLA degradation (Fig. 2). Such gain-of-function dominant mutations constitutively inhibit GA responses, including growth. Several studies have shown that these mutants are tolerant to various biotic and abiotic stresses, including drought (Magome et al., 2008; Bari et al., Bari and Jones, 2009; Nir et al., 2017). By contrast, loss-of-function, recessive mutations in the C-terminal region of DELLA are associated with constitutive GA responses (Fig. 2), resulting in excess elongation and stress-susceptible plants (Achard et al., 2006, 2008; Nir et al., 2017). 


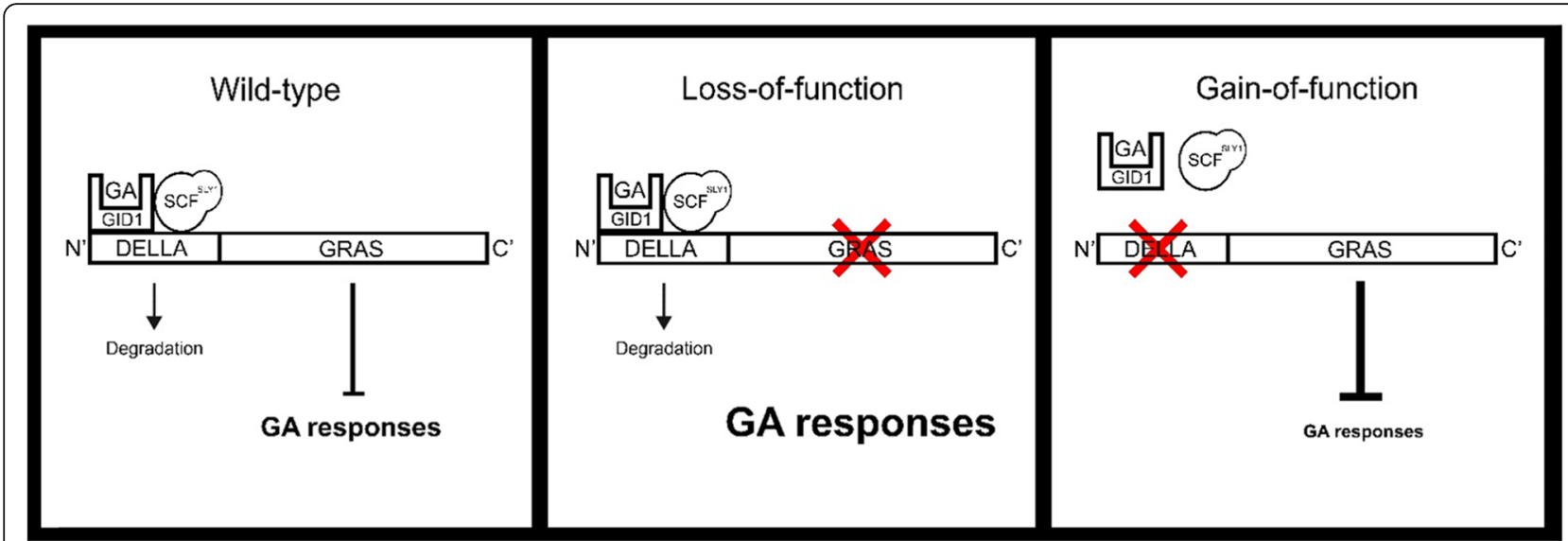

Fig. 2 Schematic presentation of the two types of DELLA mutants and their effect on GA signaling. Wild-type (left), DELLA loss-of-function (center) and gain-of-function (right) mutations. Red X represents the mutation site in DELLA

\section{GA metabolism, sensing and signaling in tomato}

Tomato is widely used as a model system for crop research; it is diploid, self-compatible, simple to cross, easy to grow and has an efficient transformation protocol. As a result, well characterized genetic materials and tools, sequenced genome and extensive gene expression profiles are available (The Tomato Genome Consortium, 2012). Studies in tomato cover many topics, including flowering, fruit development and maturation, secondary metabolism, interaction with the environment and hormone activity, in general, and GA metabolism and signaling, in particular (Serrani et al., 2007; Livne et al., 2015; Illouz-Eliaz et al., 2019; Israeli et al., 2019; Shinozaki et al., 2020).

The GA metabolism and signaling pathways in tomato are summarized in Fig. 1. gib-1, gib-2, and gib-3, three GA-deficient mutants identified and characterized in tomato (Koornneef et al., 1990; Bensen and Zeevaart, 1990) exhibit typical GA-deficiency phenotypes, including dwarfism, small and dark green leaves and delayed seed germination, all of which are corrected by application of exogenous GA (Butcher et al., 1990). GIB-1 encodes CPS, GIB-3 encodes KS and GIB-2 encodes KAO (Bensen and Zeevaart, 1990; Koornneef et al., 1990). The tomato CPS, KS and $\mathrm{KO}$ are encoded by a single gene, and $\mathrm{KAO}$, which forms $\mathrm{GA}_{12}$, has four paralogs (Pattison et al., 2015).

The later steps in the pathway are catalyzed by rather large families of 2-ODDs; 8 putative GA20ox, 6 putative GA3ox and 11 putative GA2ox (Pattison et al., 2015; Chen et al., 2016; Shohat et al., 2021). CRISPR-derived ga20ox1 and ga20ox2 mutants, recently characterized in tomato (Shohat et al., 2021), exhibit mild GA-deficiency phenotypes, including shorter stems and smaller leaves. The ga20ox1/ga20ox2 double mutant exhibited an additive effect, including severe dwarfism, dark-green, small leaves and delayed germination, suggesting that GA20ox1 and GA20ox2 play a key role in GA biosynthesis in tomato. A mutation in the tomato class III GAdeactivating gene GA2ox7 increases the levels of bioactive $\mathrm{GA}_{1}$ and $\mathrm{GA}_{4}$, and is associated with a unique phenotype, i.e., elongated internodes but normal leaves, suggesting limited stem-to-leaf transport of bioactive GAs (Schrager-Lavelle et al., 2019).

The canonical GA signal transduction pathway in tomato includes three GID1 receptors (GID1a, GID1b1 and GID1b2 (Illouz-Eliaz et al., 2019)), a single DELLA protein named PROCERA (PRO) and a single F-box protein, SLY1 (Jasinski et al., 2008; Illouz-Eliaz et al., 2019, 2020). GID1a is the dominant GA receptor with the strongest effect on stem elongation and leaf growth. In contrast, flower growth is only affected in plants bearing type B GID1 receptor mutants. The gid1 single and double mutants exhibit almost normal growth, suggesting overlapping activities and high redundancy. Seeds of the triple gid1 mutant (gid $1^{T R I}$ ) only germinate upon embryo rescue and the plants exhibit extreme dwarfism and complete insensitivity to GA.

Three pro (DELLA) loss-of-function alleles were characterized in tomato (Jasinski et al., 2008; Lor et al., 2014; Livne et al., 2015). The conserved VHVID domain in the $\mathrm{C}$-terminal region of $\mathrm{PRO}$ is required to repress GA responses (Bassel et al., 2008). A point mutation (T905 to A) in this domain, in pro, resulted in constitutive GA responses, leading to early germination, elongated stems and facultative parthenocarpy (Van Tuinen et al., 1999; Bassel et al., 2008). pro ${ }^{\triangle G R A S}$, a null mutant of PRO (Livne et al., 2015) lacks the entire $C^{\prime}$-terminal part of the protein, exhibits enhanced GA responses compared to pro, including an extremely elongated stem and obligatory parthenocarpy. Moreover, in contrast to the weak pro allele, pro ${ }^{\triangle G R A S}$ is fully insensitive to 
paclobutrazol and GA treatments. The third DELLA loss-of-function allele was generated using Transcription Activator-Like Effector Nucleases (TALENs, Lor et al., 2014). This mutant is null and phenocopies pro ${ }^{\Delta G R A S}$. Transgenic tomato plants overexpressing the gain-offunction stable DELLA mutant protein pro $\triangle 17$ which lacks the DELLA domain, exhibit a severe GA-deficient phenotype and GA insensitivity (Nir et al., 2017). Another gain-of-function allele was generated using CRISPR-Cas9 technology to target the DELLA domain in $p r o^{T A L E N}$, turning its loss-of-function nature to gainof-function (Zhu et al., 2019).

A CRISPR-derived tomato sly1 mutant exhibits severe dwarfism (Illouz-Eliaz et al., 2020). sly1 is insensitive to GA, suggesting a strong inhibition of GA signaling, confirming the importance of DELLA degradation via the proteasome pathway to relieve GA responses in tomato.

\section{The role of GA and DELLA in tomato plant response to water deficiency and adaptation to drought}

The role of DELLA in plant responses to abiotic stresses originated independently of GA; the liverwort Marchantia polymorpha DELLA ancestor regulates responses to stress despite the lack of GA and the canonical GA signaling pathway (Hernandez-Garcia et al., 2021). In higher plants, DELLA accumulation depends on GA and both, antagonistically, affect plant response to stress. Several studies in tomato have shown that inhibition of GA activity and accumulation of DELLA promote drought resistance by affecting several different metabolic and developmental processes throughout the plant life cycle, from seeds to mature plants (Fig. 3, Nir et al., 2014, 2017; Omena-Garcia et al., 2019; Illouz-Eliaz et al., 2019, 2020; Shohat et al., 2021).

\section{$G A$ and drought tolerance in tomato}

Tomato seeds are tolerant to desiccation and can germinate after years of dry storage (Priestley et al., 1985). ABA has a central role in the acquisition of desiccation tolerance (Ooms et al., 1993; Finkelstein et al., 2008) through its promotion of the activity of various major regulators of seed desiccation tolerance during seed maturation, including ABA INSENSITIVE3 (ABI3), FUSCA3 (FUS3) and LEAFY COTYLEDON1 (LEC1) and LEC2 (To et al., To A et al., 2006). GA opposes ABA activity in seeds (Groot et al., 1987; Tyler et al., 2004; Steinbrecher and Leubner-Metzger, 2017), and also affects desiccation tolerance; tomato DELLA null mutant pro $^{\triangle G R A S}$ seeds are susceptible to desiccation and fail to germinate even after short periods (days) of storage (Livne et al., 2015). This was attributed to the low expression of the ABA-regulated, drought tolerance-related genes $A B I 3$, FUS3 and LE25 in pro ${ }^{\triangle G R A S}$ seeds. It was therefore suggested that the accumulation of DELLA during seed maturation is important for the acquisition of ABAinduced long-term drought tolerance in tomato seeds.

Tolerance to drought can be acquired by osmotic adjustment, i.e., the accumulation of ions and organic solutes in the cells (Shabala and Shabala, 2011). Under water-deficit conditions, some plants accumulate high levels of solutes in their roots and leaves to reduce the cellular osmotic potential and maintain high turgor pressure (Turner, 2018). Omena-Garcia et al. (2019) reported that the GA-deficient gib-1, gib-2 and gib-3 tomato mutants accumulate higher levels of osmolytes, and were able to maintain higher leaf water content and leaf turgor under water-deficit conditions.

\section{$G A$ and 'drought avoidance' in tomato}

All higher plants respond to water limitation by rapid stomatal closure and inhibition of shoot growth (Brunner et al., 2015). These responses reduce transpiration and water loss (Skirycz and Inzé, 2010). Nir et al. (2014) showed that inhibition of bioactive GA accumulation in tomato by overexpressing the Arabidopsis GAMT1 gene, reduces water loss under drought conditions. The reduced transpiration in the transgenic plants was ascribed to the smaller leaves and to reduced stomatal aperture. Later, Nir et al. (2017) showed that overexpression of the stable DELLA protein pro $\triangle 17$ in tomato plants reduced stomatal aperture and transpiration, independently of leaf growth. Moreover, targeted overexpression of pro $\Delta 17$ in guard cells was sufficient to reduce stomatal aperture, suggesting that PRO acts in guard cells in a cell-autonomous manner. In line with this, the DELLA loss-of-function pro mutant exhibits increased stomatal conductance and water loss under water-deficit conditions. This effect of GA/DELLA is likely part of the natural 'drought avoidance' response in tomato; under water-deficit conditions the expression of the GA deactivation gene GA2ox7 is strongly upregulated in guard cells, leading to reduced levels of bioactive stomatal GAs (Shohat et al., 2021). This upregulation of GA2ox7 is required for the rapid stomatal response to drought, as the loss of GA2ox7 activity inhibited stomatal closure in the early stages of soil dehydration (Shohat et al., 2021). A role for GA in stomatal movement was also described in Commelina benghalensis, Vicia faba and Fritillaria imperialis, where GA application increased stomatal aperture (Santakumari and Fletcher, 1987; Goring et al., 1990).

The effects of pro $\Delta 17$ on stomatal closure and water loss were suppressed in the ABA-deficient sitiens (sit) tomato mutant, indicating that the effect of DELLA is ABA-dependent. While DELLA did not affect ABA levels, increased DELLA activity promoted ABA responses in guard cells (Nir et al., 2017; Shohat et al., 2020). RNAseq analysis of isolated guard cells derived 


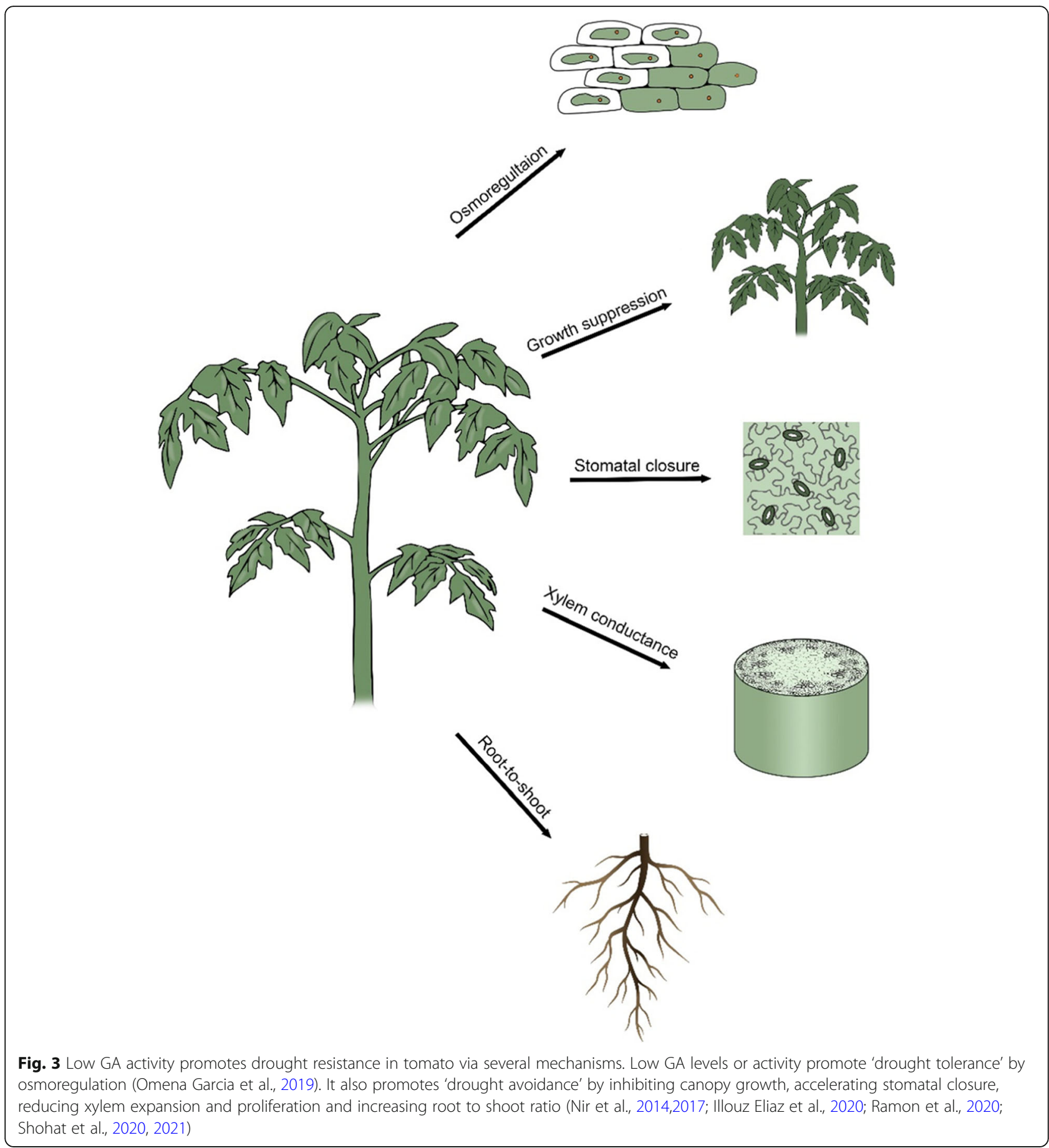

from tomato plants with high versus low DELLA (PRO) activity, identified the ABA transporter ABA-IMPORTING TRANSPORTER 1.1 (AIT1.1) as upregulated by PRO (Shohat et al., 2020). The CRISPR-derived ait1.1 mutant exhibits increased transpiration and reduced ABA-induced stomatal closure. ait1.1 also suppresses the promoting effect of DELLA on stomatal closure, suggesting that most, if not all, of the effects of GA/DELLA on stomatal response to water deficiency are related to the negative cross-talk between GA and ABA.

GA and DELLA also impact 'drought avoidance' through developmental responses. Reduced transpiration throughout prolonged periods of water deficiency is also achieved by growth suppression and the reduction of transpiration area (Salah and Tardieu, 1997). Several studies suggest that inhibition of GA accumulation 
under water-deficit conditions plays a role in droughtinduced growth suppression (Skirycz and Inzé, 2010; Litvin et al., 2016). For example, low levels of GA in Populus inhibit growth and promote resistance to waterdeficit conditions (Zawaski and Busov, 2014). Drought conditions inhibit GA accumulation in maize leaf elongation-zones and suppress their growth (Nelissen et al., 2018). The reduced GA levels in tomato under water-deficit conditions is a results of both, inhibition of GA biosynthesis and activation of GA catabolism (Litvin et al., 2016; Shohat et al., 2021). Water-deficit conditions inhibit the expression of the GA biosynthesis genes GA200x1 and GA200x2, promote the expression of GA2ox7, reduce the levels of bioactive GAs and suppress leaf expansion (Shohat et al., 2021). ga20ox1 and ga20ox2 mutants exhibit reduced whole-plant transpiration under water-deficit conditions due to their smaller canopy area.

While shoot growth is inhibited under water-deficit conditions, root growth is maintained, and even promoted, leading to increased root-to-shoot ratio (Sharp et al., 2004). These developmental changes improve water balance under water-limited conditions. Some evidence implies that GA has a role in altering root-toshoot ratio under water-deficit conditions. Although GA promotes root elongation in Arabidopsis (Yaxley et al., 2001; Fu and Harberd, 2003), in some other species, GA has no effect or even suppresses root growth (Berova and Zlatev, 2000; Gou et al., 2010; Fonouni-Farde et al., 2019; Moriconi et al., 2019). Reduced GA levels or signaling promote lateral root density and growth in Populus (Gou et al., 2010). In Medicago, GA inhibits and the GA biosynthesis inhibitor paclobutrazol, promotes primary root elongation and lateral root counts (Fonouni-Farde et al., 2019). The DELLA loss-offunction $\sin 1$ barley mutant exhibits reduced root growth (Moriconi et al., 2019). In tomato, GA has a strong effect on shoot growth, but only a minor effect on primary root elongation (Ramon et al., 2020). In line with this, gid $^{T R I}$ exhibits a dramatically increased rootto-shoot ratio due to the strong inhibition of shoot growth, but only a mild effect on root elongation. Thus, inhibition of GA accumulation upon water deficiency is expected to restrict shoot growth without conferring an effect on root elongation and therefore, may contribute to the increased root-to-shoot ratio.

Low GA activity also reduces water loss in tomato through changes in the hydraulic conductivity; low GA activity in gidla or sly1 mutants inhibits xylem-vessel expansion and proliferation and reduces hydraulic conductivity (Illouz-Eliaz et al., 2020). Under severe drought conditions, the effect of low GA activity on xylem expansion can also protect plants from cavitation and embolism (Ishihara and Hirasawa, 1978; Baum et al., 1999;
Brodribb and Hill, 2000). Thus, inhibition of xylem expansion and proliferation by low GA activity may be another mechanism through which reduced GA promotes adaptation to prolonged periods of limited water.

\section{Harnessing the GA pathway to improve tomato performance under water-limited conditions}

Manipulation of the GA pathway has enormous potential in crop improvement (Eshed and Lippman, 2019). Mutations in the GA biosynthesis or signaling pathways have been used to improve crops. The best example is the introduction of semi-dwarf cereal crops in the 1960s, which led to a significant increase in yield. The semidwarf varieties are resistant to lodging even when excessively fertilized (Wu et al., 2020). Two major types of mutations are responsible for what has come to be known as the 'Green Revolution' (Hedden, 2003); a lossof-function mutation in the $S D 1$ gene encoding the GA biosynthesis enzyme GA20ox2 in rice (Monna et al., 2002; Sasaki et al., 2002; Spielmeyer et al., 2002), and a gain-of-function mutation in Rht1, a gene encoding DELLA in wheat (Peng et al., 1999).

As described above, the GA pathway can also be harnessed in tomato to enhance resistance to abiotic stresses, including drought. Since GA and DELLA have a pleotropic effect on growth, a trade-off between yield and drought resistance is expected. However, this might only be true for strong inhibition of GA activity. IllouzEliaz et al. (2020) showed that while mutation in a single GA receptor (GID1a) suppressed growth in the field, it had no effect on yield, giving rise to a tomato line with a higher harvest index (fruit weight/plant fresh weight). This is a desired side-effect of GA inhibition, in that it allows higher planting density to obtain higher yield per unit area (Gifford and Evans, 1981). Thus, the ultimate goal is to generate mutants with mild dwarfism, normal yield under well-watered conditions and significantly improved drought resistance. Introduction of the CRISPR technology has made this more feasible to achieve within a relatively short time (Jinek et al., 2012; Brooks et al., 2014), in contrast to the decades required when using classical breeding (Bai and Lindhout, 2007). CRISPRbased technologies provide a variety of genome-editing tools, including targeted mutation knockouts (KOs), tissue-specific KOs, multiplex gene editing, targeted insertion, gene activation and precise genome editing (Brooks et al., 2014; Rodríguez-Leal et al., 2017; Zhu et al., 2020; Dong and Ronald, 2021; Pan et al., 2021). CRISPR has already been applied to improve the agronomical traits of an orphan Solanaceae crop (Physalis pruinosa) and a wild tomato species (Solanum pimpinellifolium), by simultaneously editing four genes involved in plant architecture (SP), flowering time 
(SP5G) and fruit size (SICLV1/3 and SlWUS) (Lemmon et al., 2018; Li et al., 2018).

\section{Possible GA pathway targets for CRISPR-based mutagenesis to increase drought resistance in tomato}

Transduction of the GA signal is based on a cascade of interactions, i.e., GA with GID1, GID1 with DELLA and DELLA with SLY1. The possible interaction sites between these three signaling components are presented in Fig. 4, and described elaborately by McGinnis et al. (2003), Murase et al. (2008) Hirano et al., (2010). Attenuating without eliminating the affinity between these interacting components, may lead to mild growth suppression without affecting yield, but with increased drought resistance. A rapid and efficient way to do so is by applying precise CRISPR-based genome-editing tools such as base editing (single base-pair substitution/deletion, Zhu et al., 2020).

Perturbations of GA binding to GID1 can be obtained by site-specific mutations in the GA binding "pocket" of GID1 (Murase et al., 2008). Attenuating the affinity of GID1 to DELLA (PRO) can be achieved by mutations in the GID1 N-terminal extension (NEx) domain (Murase et al., 2008) or by mutations in the N-terminal region of PRO (GID1 binding site). However, deletion of PRO's N-terminal causes severe dwarfism (Zhu et al., 2019). Thus, mutations in other sites, outside the $\mathrm{N}$-terminal region, that affect GID1 binding, may generate weak gain-of-function alleles, as shown before in rice (Hirano et al., 2010). A mild reduction in GA signaling can also be obtained by interfering with the DELLA-SLY1 interaction. SLY1 has two conserved domains required for its interaction with DELLA, i.e., the GGF domain and the LSL domain (McGinnis et al., 2003). A CRISPRderived tomato sly1 mutant, which carries a single nucleotide insertion, causing a frame shift and premature stop codon before the LSL domain, was already generated, but has a severe dwarf phenotype (IllouzEliaz et al., 2020). Using the same precise editing techniques to generate weak sly1 alleles which only reduces the affinity to DELLA, may provide finetuning of GA responses only.

Attenuation of GA signaling can also be achieved using multiple guide constructs to target various cisregulatory elements in the promoters of GID1s, PRO or SLY1. This is expected to generate a collection of alleles exhibiting changes in the expression levels and patterns and their subsequent activity, and to enable selection of drought-tolerant lines. It should be noted, however, that DELLAs are primarily regulated at the post-translational level (Blanco-Tourinan et al., 2020). Thus, this approach seems to be more relevant to GID1s and SLY1.

The GA signaling components in tomato are encoded by a small number of genes (single $P R O$ and SLY1 and three GID1s). Thus, mutation in a single gene might lead to undesired phenotypic changes and yield loss. Illouz-Eliaz et al. $(2019,2020)$ show that although the gid1a mutant grows well under stable conditions, it exhibits phenotypic instability when grown under extreme, unstable environmental conditions in the field, leading, in some plants, to strong growth suppression and yield loss. Growth and yield instability might be prevented if the target gene belongs to a large family. For example, the enzymes in the later stages of the GA biosynthetic pathway are encoded by rather large gene families in all plant species. The tomato genome encodes 8 GA20oxs and 6 GA3oxs (Pattison et al., 2015). Several studies show that enzymes from these groups exhibit tissue-specific expression (Serrani et al., 2007; Chen et al., 2016). According to their spatial expression pattern (http:// bar.utoronto.ca/efp_tomato/cgi-bin/efpWeb.cgi),

GA200x1 and GA20ox2 seems to be the best candidates for the generation of drought-resistant plants with no, or a weak effect on yield. Indeed, ga20ox1 and ga20ox2 mutants exhibit a mild growth phenotype and reduced water loss under drought conditions (Shohat et al., 2021).

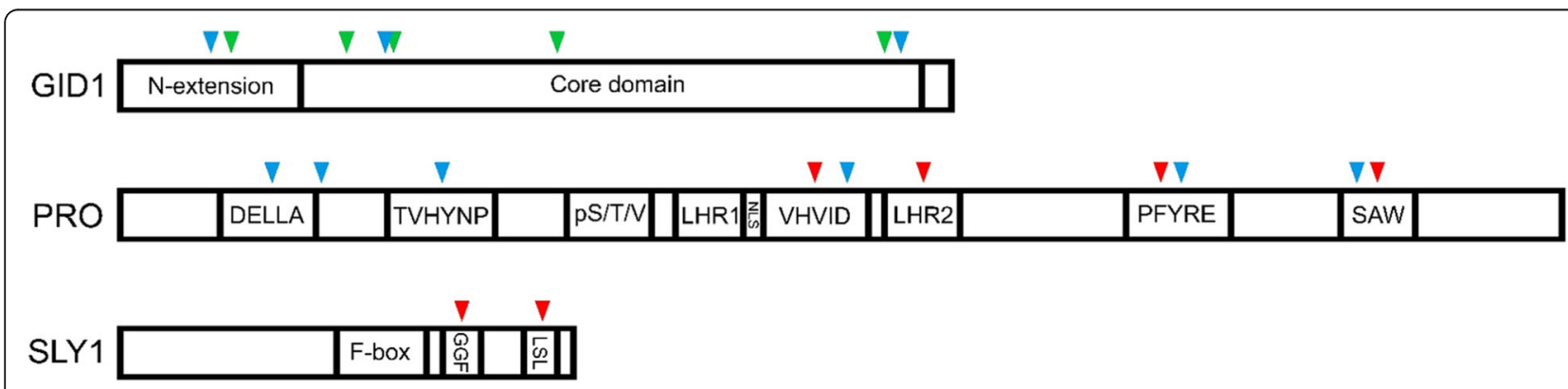

Fig. 4 Possible target sites in the major tomato signaling components to attenuate without eliminate GA responses. GA-GID1 interaction sites are indicated by green arrows, GID1-PRO interaction by blue arrows and PRO-SLY1 interaction by red arrows. The specific sites in homologous GID1, DELLA and SLY1 are elaborated in McGinnis et al., (2003), Murase et al., (2008) and Hirano et al., (2010) 
In conclusion, manipulations of the GA pathway in tomato can be exploited to improve drought resistance, as well as resistance to other abiotic and biotic stresses. Alongside resistance, these modifications may improve yield through their effect on plant architecture and harvest index. Further research will still be necessary to develop high-yield tomato plants with improved stress resistance using the GA pathway, and will be made possible using the recent advances in gene-editing technologies.

\section{Abbreviations}

2-ODDs: 2-oxoglutarate-dependent dioxygenases; ABA: Abscisic acid; ABI3: ABA INSENSITIVE3; AIT1.1: ABA-IMPORTING TRANSPORTER 1.1; CLV: CLAVATA; CPS: Copalyl diphosphate synthase; CRISPR: Clustered regularly interspaced short palindromic repeats; FUS3: FUSCA3; GA: Gibberellin; GA13ox: GA 13-oxidase; GA2ox: GA 2-oxidase; GA20ox: GA 20-oxidase; GA3ox: GA 3-oxidase; GAMT1: GA METHYL TRANSFERASE1; GGPP: Geranylgeranyl diphosphate; GID1: GIBBERELLIN INSENSITIVE DWARF 1; KAO: Kaurenoic acid oxidase; KO: Kaurene oxidase; KOs: Knockouts; KS: Kaurene synthase; LEC: LEAFY COTYLEDON; N-Ex: N-terminal extension; PRO: PROCERA; ROS: Reactive oxygen species; SD1: SEMIDWARF 1; sit: sitiens; SLY1: SLEEPY1; SP: SELF-PRUNING; SP5G: SELF-PRUNING 5G;

TALEN: Transcription activator-like effector nucleases; WUS: WUSCHEL

\section{Acknowledgements}

Not applicable.

\section{Authors' contributions}

HS and DW conceived and design the content of the review. HS, NIE and DW wrote the manuscript. All authors red and approved the final version of the manuscript.

\section{Authors' information}

Not applicable.

\section{Funding}

This research was supported by the Israel Science Foundation (617/20) to DW.

\section{Availability of data and materials}

All data presented in this review is included in this published manuscript.

\section{Declarations}

Ethics approval and consent to participate

Not applicable.

\section{Consent for publication}

Not applicable.

\section{Competing interests}

The authors declare no competing interests.

\section{Author details}

'Institute of Plant Sciences and Genetics in Agriculture, The Hebrew University of Jerusalem, P.O. Box 12, 76100 Rehovot, Israel. ${ }^{2}$ Plant Biology Laboratory, The Salk Institute for Biological Studies, La Jolla, CA 92037, USA.

Received: 15 August 2021 Accepted: 5 November 2021 Published online: 24 November 2021

\section{References}

Achard P, Cheng H, De Grauwe L, Decat J, Schoutteten H, Moritz T, et al. Integration of plant responses to environmentally activated phytohormonal signals. Science. 2006;311(5757):91-4. https://doi.org/10.1126/science.111 8642.
Achard P, Renou JP, Berthomé R, Harberd NP, Genschik P. Plant DELLAs restrain growth and promote survival of adversity by reducing the levels of reactive oxygen species. Curr Biol. 2008;18(9):656-60. https://doi.org/10.1016/j.cub.2 008.04.034.

Bai Y, Lindhout P. Domestication and breeding of tomatoes: what have we gained and what can we gain in the future? Ann Bot. 2007;100(5):1085-94. https://doi.org/10.1093/aob/mcm150.

Bari R, Jones JDG. Role of plant hormones in plant defense responses. Plant Mol Biol. 2009;69(4):473-88. https://doi.org/10.1007/s11103-008-9435-0.

Bassel GW, Mullen RT, Bewley JD. Procera is a putative DELLA mutant in tomato (Solanum lycopersicum): effects on the seed and vegetative plant. J Exp Bot. 2008:59(3):585-93. https://doi.org/10.1093/jxb/erm354.

Baum SF, Tran PN, Silk WK. Effects of salinity on xylem structure and water use in growing leaves of sorghum. New Phytol. 1999;146(1):119-27. https://doi. org/10.1046/j.1469-8137.2000.00625.x.

Bensen RJ, Zeevaart JAD. Comparison of Ent-kaurene synthetase $a$ and B activities in cell-free extracts from young tomato fruits of wild-type and gib-1, gib-2, and gib-3 tomato plants. J Plant Growth Regul. 1990;9(1-4):237-42. https://doi.org/10.1007/BF02041969.

Berova M, Zlatev Z. Physiological response and yield of paclobutrazol treated tomato plants (Lycopersicon esculentum Mill.). Plant Growth Regulation. 2000; 30:117-23.

Blanco-Tourinan N, Serrano-Mislata A, Alabadi D. Regulation of DELLA proteins by post-translational modifications. Plant Cell Physiol. 2020;61(11):1891-901. https://doi.org/10.1093/pcp/pcaa113.

Brodribb TJ, Hill RS. Increases in water potential gradient reduce xylem conductivity in whole plants. Evidence from a low-pressure conductivity method. Plant Physiol. 2000;123(3):1021-8. https://doi.org/10.1104/pp.123.3.1021.

Brooks C, Nekrasov V, Lippman ZB, Eck JV. Efficient gene editing in tomato in the first generation using the clustered regularly interspaced short palindromic repeats/CRISPR-associated9 system. Plant Physiol. 2014;166(3):1292-7. https:// doi.org/10.1104/pp.114.247577.

Brunner I, Herzog C, Dawes MA, Arend M, Sperisen C. How tree roots respond to drought. Front Plant Sci. 2015;6:547. https://doi.org/10.3389/fpls.2015.00547.

Butcher DN, Clark JA, Lenton JR. Gibberellins and the growth of excised tomato roots: comparison of gib-1 mutant and wild type and responses to applied $\mathrm{GA}_{3}$ and 2S,3S paclobutrazol. J Exp Bot. 1990;41(6):715-22. https://doi.org/1 $0.1093 / \mathrm{jxb} / 41.6 .715$

Chaves MM, Maroco JP, Pereira JS. Understanding plant responses to droughtfrom genes to the whole plant. Funct Plant Biol. 2003;30(3):239-64. https:// doi.org/10.1071/FP02076.

Chen S, Wang X, Zhang L, Lin S, Liu D, Wang $Q$, et al. Identification and characterization of tomato gibberellin 2-oxidases (GA2oxs) and effects of fruit-specific S/GA20x1 overexpression on fruit and seed growth and development. Hortic Res. 2016;3(1):16059. https://doi.org/10.1038/hortres.2 016.59 .

Colebrook EH, Thomas SG, Phillips AL, Hedden P. The role of gibberellin signaling in plant responses to abiotic stress. J Exp Biol. 2014;217(1):67-75. https://doi. org/10.1242/jeb.089938.

Cutler SR, Rodriguez PL, Finkelstein RR, Abrams SR. Abscisic acid: emergence of a Core signaling network. Ann Rev Plant Biol. 2010;61 (1):651-79. https://doi. org/10.1146/annurev-arplant-042809-112122.

Dai A. Drought under global warming: a review. Wiley Interdiscip Rev Clim Chang. 2011;2(1):45-65. https://doi.org/10.1002/wcc.81.

Daviere JM, Achard P. Gibberellin signaling in plants. Development. 2013;140(6): 1147-51. https://doi.org/10.1242/dev.087650.

Dietrich D. Hydrotropism: how roots search for water. J Exp Bot. 2018;69(11): 2759-71. https://doi.org/10.1093/jxb/ery034.

Dill A, Thomas S, Hu J, Steber C, Sun TP. The Arabidopsis F-box protein SLEEPY1 targets gibberellin signaling repressors for gibberellin-induced degradation. Plant Cell. 2004;16(6):1392-405. https://doi.org/10.1105/tpc.020958.

Dong OX, Ronald PC. Targeted DNA insertion in plants. Proc Natl Acad Sci U S A. 2021;118(22):e2004834117. https://doi.org/10.1073/pnas.2004834117.

Eshed Y, Lippman ZB. Revolutions in agriculture chart a course for targeted breeding of old and new crops. Science. 2019;366:eaax0025.

Farber M, Attia Z, Weiss D. Cytokinin activity increases stomatal density and transpiration rate in tomato. J Exp Bot. 2016;67(22):6351-62. https://doi.org/1 0.1093/jxb/erw398.

Feng W, Lindner H, Robbins NE II, Dinneny JR. Growing out of stress: the role of cell- and organ-scale growth control in plant water-stress responses. Plant Cell. 2016;28(8):1769-82. https://doi.org/10.1105/tpc.16.00182. 
Finkelstein R, Reeves W, Ariizumi T, Steber C. Molecular aspects of seed dormancy. Ann Rev Plant Biol. 2008;59(1):387-415. https://doi.org/10.1146/a nnurev.arplant.59.032607.092740.

Fonouni-Farde C, Miassod A, Laffont C, Morin H, Bendahmane A, Diet A, et al. Gibberellins negatively regulate the development of Medicago truncatula root system. Sci Rep. 2019;9(1):2335. https://doi.org/10.1038/ s41598-019-38876-1.

Fu X, Harberd NP. Auxin promotes Arabidopsis root growth by modulating gibberellin response. Nature. 2003;421(6924):740-3. https://doi.org/10.1038/ nature01387.

Gifford RM, Evans LT. Photosynthesis, carbon partitioning, and yield. Ann Rev Plant Physiol. 1981;32(1):485-509. https://doi.org/10.1146/annurev.pp.32.0601 81.002413

Gong P, Zhang J, Li H, Yang C, Zhang C, Zhang X, et al. Transcriptional profiles of drought-responsive genes in modulating transcription signal transduction, and biochemical pathways in tomato. J Exp Bot. 2010;61(13):3563-75. https:// doi.org/10.1093/jxb/erq167.

Goring $H$, Koshuchowa S, Deckert C. Influence of gibberellic acid on stomatal movement. Biochem Physiol Pflanzen. 1990;186(5-6):367-74. https://doi.org/1 0.1016/S0015-3796(11)80235-0.

Gou J, Strauss SH, Tsai CJ, Fang K, Chen Y, Jiang X, et al. Gibberellins regulate lateral root formation in Populus through interactions with auxin and other hormones. Plant Cell. 2010;22(3):623-39. https://doi.org/10.1105/tpc.109. 073239.

Griffiths J, Murase K, Rieu I, Zentella R, Zhang ZL, Powers SJ, et al. Genetic characterization and functional analysis of the GID1 gibberellin receptors in Arabidopsis. Plant Cell. 2006;18(12):3399-414. https://doi.org/10.1105/tpc.106. 047415.

Groot SPC, Bruinsma J, Karssen CM. The role of endogenous gibberellin in seed and fruit development: studies with a gibberellin-deficient mutant. Physiol Plant. 1987;71(2):184-90. https://doi.org/10.1111/j.1399-3054.1987.tb02865.x.

Gupta A, Rico-Medina A, Cano-Delgado Al. The physiology of plant responses to drought. Science. 2020;386(6488):266-9. https://doi.org/10.1126/science.aa z7614.

Gur A, Zamir D. Unused natural variation can lift yield barriers in plant breeding PLoS Biol. 2004;2(10):e245. https://doi.org/10.1371/journal.pbio.0020245.

Harberd NP, Belfield E, Yasumura Y. The angiosperm gibberellin-GID1-DELLA growth regulatory mechanism: how an 'inhibitor of an inhibitor' enables flexible response to fluctuating environments. Plant Cell. 2009;21(5):1328-39. https://doi.org/10.1105/tpc.109.066969.

Hauvermale AL, Ariizumi T, Steber CM. Gibberellin signaling: a theme and variations on DELLA repression. Plant Physiol. 2012;160(1):83-92. https://doi. org/10.1104/pp.112.200956

Hedden P. The genes of the green revolution. Trends Genet. 2003;19(1):5-9 https://doi.org/10.1016/S0168-9525(02)00009-4

Hedden P. The current status of research on gibberellin biosynthesis. Plant Cell Physiol. 2020;61(11):1832-49. https://doi.org/10.1093/pcp/pcaa092.

Hernandez-Garcia J, Sun R, Serrano-Mistala A, Inoue K, Vargas-Chavez C, EsteveBruna $D$, et al. Coordination between growth and stress responses by DELLA in the liverwort Marchantia polymorpha. Curr Biol. 2021;31(16):1-9. https:// doi.org/10.1016/j.cub.2021.06.010.

Hirano K, Asano K, Tsuji H, Kawamura M, Mori H, Kitano H, et al. Characterization of the molecular mechanism underlying gibberellin perception complex formation in rice. Plant Cell. 2010;22(8):2680-96. https://doi.org/10.1105/ tpc.110.075549.

Illouz-Eliaz N, Nissan I, Nir I, Ramon U, Shohat H, Weiss D. Mutations in the tomato gibberellin receptors suppress xylem proliferation and reduce water loss under water-deficit conditions. J Exp Bot. 2020;71(12):3603-12. https:// doi.org/10.1093/jxb/eraa137.

Illouz-Eliaz N, Ramon U, Shohat H, Blum S, Livne S, Mendelson D, et al. Multiple gibberellin receptors contribute to phenotypic stability under changing environments. Plant Cell. 2019;31(7):1506-19. https://doi.org/10.1105/tpc.19.00235.

lovieno P, Punzo P, Guida G, Mistretta C, Van Oosten MJ, Nurcato R, et al. Transcriptomic changes drive physiological responses to progressive drought stress and rehydration in tomato. Front Plant Sci. 2016;7:371. https://doi.org/1 0.3389/fpls.2016.00371.

Ishihara K, Hirasawa T. Relationship between leaf and xylem water potentials in rice plants. Plant Cell Physiol. 1978;19:1289-94.

Israeli A, Capua Y, Shwartz I, Tal L, Meir Z, Levy M, et al. Multiple auxin-response regulators enable stability and variability in leaf development. Curr Biol. 2019; 29(11):1746-59. https://doi.org/10.1016/j.cub.2019.04.047.
Jasinski S, Tattersall A, Piazza P, Hay A, Martinez-Garcia JF, Schmitz G, et al. PROCERA encodes a DELLA protein that mediates control of dissected leaf form in tomato. Plant J. 2008;56(4):603-12. https://doi.org/10.1111/j.1365-313 X.2008.03628.X.

Jinek M, Chylinsky K, Fonfara I, Hauer M, Doudna JA, Charpentier E. A programmable dual-RNA-guided DNA endonuclease in adaptive bacterial immunity. Science. 2012;337(6096):816-21. https://doi.org/10.1126/ science. 1225829

Koornneef M, Bosma TDG, Hanhart CJ, van der Veen JH, Zeevaart JAD. The isolation and characterization of gibberellin-deficient mutants in tomato. Theor Appl Genet. 1990;80(6):852-7. https://doi.org/10.1007/ BF00224204.

Kooyers NJ. The evolution of drought escape and avoidance in natural herbaceous populations. Plant Sci. 2015;234:155-62. https://doi.org/10.1016/j. plantsci.2015.02.012.

Lemmon ZH, Reem NT, Dalrymple J, Soyk S, Swartwood KE, Rodriguez-Leal D, et al. Rapid improvement of domestication traits in an orphan crop by genome editing. Nat Plants. 2018;4(10):766-70. https://doi.org/10.1038/s414 77-018-0259-X.

Li T, Yang X, Yu Y, Si X, Zhai X, Zhang H, et al. Domestication of wild tomato is accelerated by genome editing. Nat Biotechnol. 2018;36(12):1160-3. https:// doi.org/10.1038/nbt.4273.

Lind C, Dreyer I, López-Sanjurjo EJ, von Meyer K, Ishizaki K, Kohchi T, et al. Stomatal guard cells co-opted an ancient ABA-dependent desiccation survival system to regulate stomatal closure. Curr Biol. 2015;25(7):928-35. https://doi.org/10.1016/j.cub.2015.01.067.

Litvin A, van lersel MW, Malladi A. Drought stress reduces stem elongation and alters gibberellin-related gene expression during vegetative growth of tomato. J Amer Soc Hort Sci. 2016;141(6):591-7. https://doi.org/10.21273/JA SHS03913-16.

Livne S, Lor VS, Nir I, Eliaz N, Aharoni A, Olszewski NE, et al. Uncovering DELLA-independent gibberellin responses by characterizing new tomato procera mutants. Plant Cell. 2015;27(6):1579-94. https://doi.org/10.1105/ tpc.114.132795.

Locascio A, Blázquez MA, Alabadí D. Genomic analysis of della protein activity. Plant Cell Physiol. 2013;54(8):1229-37. https://doi.org/10.1093/pcp/pct082.

Lor VS, Starker CG, Voytas DF, Weiss D, Olszewski NE. Targeted mutagenesis of the tomato PROCERA gene using transcription activator-like effector nucleases. Plant Physiol. 2014;166(3):1288-91. https://doi.org/10.1104/ pp.114.247593.

Magome H, Yamaguchi S, Hanada A, Kamiya Y, Oda K. The DDF1 transcriptional activator upregulates expression of a gibberellin-deactivating gene, GA20X7, under high-salinity stress in Arabidopsis. Plant J. 2008;56(4):613-26. https:// doi.org/10.1111/j.1365-313X.2008.03627.X.

McGinnis KM, Thomas SG, Soule JD, Strader LC, Zale JM, Sun TP, et al. The Arabidopsis SLEEPY1 gene encodes a putative F-box subunit of an SCF E3 ubiquitin ligase. Plant Cell. 2003;15(5):1120-30. https://doi.org/10.1105/tpc.01 0827.

Monna L, Kitazawa N, Yoshino R, Suzuki J, Masuda H, Maehara Y, et al. Positional cloning of rice semidwarfing gene, sd-1: rice "green revolution gene" encodes a mutant enzyme involved in gibberellin synthesis. DNA Res. 2002; 9(1):11-7. https://doi.org/10.1093/dnares/9.1.11.

Moriconi Jl, Kotula L, Santa-Maria GE, Colmer TD. Root phenotypes of dwarf and "overgrowth" SLN1 barley mutants, and implications for hypoxic stress tolerance. J Plant Physiol. 2019;234-5:60-70.

Munns R, Tester M. Mechanisms of salinity tolerance. Ann Rev Plant Biol. 2008; 59(1):51-81. https://doi.org/10.1146/annurev.arplant.59.032607.092911.

Murase K, Hirano Y, Sun TP, Hakoshima T. Gibberellin-induced DELLA recognition by the gibberellin receptor GID1. Nature. 2008;456(7221):459-64. https://doi. org/10.1038/nature07519.

Navarro L, Bari R, Achard P, Lisón P, Nemri A, Harberd NP, et al. DELLAs control plant immune responses by modulating the balance of jasmonic acid and salicylic acid signaling. Curr Biol. 2008;18(9):650-5. https://doi.org/10.1016/j. cub.2008.03.060.

Nelissen H, Sun XH, Rymen B, Jikumaru Y, Kojima M, Takebayashi Y, et al. The reduction in maize leaf growth under mild drought affects the transition between cell division and cell expansion and cannot be restored by elevated gibberellic acid levels. Plant Biotechnol J. 2018;16(2):615-27. https://doi.org/1 $0.1111 /$ pbi.12801

Nir I, Moshelion M, Weiss D. The Arabidopsis GIBBERELLIN METHYL TRANSFERASE 1 suppresses gibberellin activity, reduces whole-plant transpiration and 
promotes drought tolerance in transgenic tomato. Plant Cell Environ. 2014; 37(1):113-23. https://doi.org/10.1111/pce.12135.

Nir I, Shohat H, Panizel I, Olszewski NE, Aharoni A, Weiss D. The tomato DELLA protein PROCERA acts in guard cells to promote stomatal closure. Plant Cell. 2017;29(12):3186-97. https://doi.org/10.1105/tpc.17.00542.

Nishiyama R, Watanabe Y, Fujita Y, Le DT, Kojima M, Werner T, et al. Analysis of cytokinin mutants and regulation of cytokinin metabolic genes reveals important regulatory roles of cytokinins in drought, salt and abscisic acid responses, and abscisic acid biosynthesis. Plant Cell. 2011;23(6):2169-83. https://doi.org/10.1105/tpc.111.087395.

Omena-Garcia R, Martins A, Medeiros D, Vallarino J, Ribeiro D, Fernie A, et al. Growth and metabolic adjustments in response to gibberellin deficiency in drought stressed tomato plants. Environ Exp Bot. 2019;159:95-107. https:// doi.org/10.1016/j.envexpbot.2018.12.011.

Ooms JJ, Leon-Kloosterziel KM, Bartels D, Koornneef M, Karssen CM. Acquisition of desiccation tolerance and longevity in seeds of Arabidopsis thaliana (a comparative study using abscisic acid-insensitive abi3 mutants). Plant Physiol. 1993;102(4):1185-91. https://doi.org/10.1104/pp.102.4.1185.

Pan C, Wu X, Markel K, Malzahn AA, Kundagrami N, Sretenovic S, et al. CRISPRAct3.0 for highly efficient multiplexed gene activation in plants. Nat Plants. 2021;7:942-53.

Pattison RJ, Csukasi F, Zheng Y, Fei Z, Van Der Knaap E, Catala C. Comprehensive tissue-specific transcriptome analysis reveals distinct regulatory programs during early tomato fruit development. Plant Physiol. 2015;168(4):1684-701. https://doi.org/10.1104/pp.15.00287.

Peng J, Richards DE, Hartley NM, Murphy GP, Devos KM, Flintham JE, et al. "Green revolution" Genes Encode Mutant Gibberellin Response Modulator. Nature. 1999;400(6741):256-61. https://doi.org/10.1038/22307.

Planas-Riverola A, Gupta A, Betegón-Putze I, Bosch N, Ibañes M, Caño-Delgado Al. Brassinosteroid signaling in plant development and adaptation to stress. Development. 2019;146:dev151894

Priestley DA, Cullinan VI, Wolfe J. Differences in seed longevity at the species level. Plant Cell Environ. 1985;8(8):557-62. https://doi.org/10.1111/j.1365-304 0.1985.tb01693.x

Rademacher W. Chemical regulators of gibberellin status and their application in plant production. Ann Plant Rev. 2016;49:359-403. https://doi.org/10.1002/ 9781119210436.ch12.

Ramon U, Weiss D, Illouz-Eliaz N. Underground gibberellin activity: differential gibberellin response in tomato shoots and roots. New Phytol. 2020;229(3): 1196-200. https://doi.org/10.1111/nph.16876.

Rodríguez-Leal D, Lemmon ZH, Man J, Bartlett ME, Lippman ZB. Engineering quantitative trait variation for crop improvement by genome editing. Cell. 2017;171(2):470-80. https://doi.org/10.1016/j.cell.2017.08.030.

Salah $\mathrm{H}$, Tardieu F. Control of leaf expansion rate of droughted maize plants under fluctuating evaporative demand (a superposition of hydraulic and chemical messages?). Plant Physiol. 1997;114(3):893-900. https://doi.org/10.11 04/pp.114.3.893.

Salehin M, Li B, Tang M, Katz E, Song L, Ecker JR, et al. Auxin-sensitive aux/IAA proteins mediate drought tolerance in Arabidopsis by regulating glucosinolate levels. Nat Commun. 2019;10(1):4021. https://doi.org/10.1038/ s41467-019-12002-1.

Santakumari M, Fletcher RA. Reversal of triazole-induced stomatal closure by gibberellic acid and cytokinins in Commelina benghalensis. Physiol Plant. 1987;71(1):95-9. https://doi.org/10.1111/j.1399-3054.1987.tb04623.x.

Sasaki A, Ashikari M, Ueguchi-Tanaka M, Itoh H, Nishimura A, Swapan D, et al. Green revolution: a mutant gibberellin-synthesis gene in rice. Nature. 2002; 416(6882):701-2. https://doi.org/10.1038/416701a.

Sasaki A, Itoh H, Gomi K, Ueguchi-Tanaka M, Ishiyama K, Kobayashi M, et al. Accumulation of phosphorylated repressor for gibberellin signaling in an Fbox mutant. Science. 2003;229(5614):1896-8. https://doi.org/10.1126/ science. 1081077 .

Schrager-Lavelle A, Gath NN, Devisetty UK, Carrera E, Lopez-Diaz I, Blazquez MA, et al. The role of a class III gibberellin 2-oxidase in tomato internode elongation. Plant J. 2019;97(3):603-15. https://doi.org/10.1111/ tpj.14145.

Serrani JC, Sanjuan R, Ruiz-Rivero O, Fos M, Garcia-Martinez JL. Gibberellin regulation of fruit set and growth in tomato. Plant Physiol. 2007;145(1):24657. https://doi.org/10.1104/pp.107.098335.

Shabala S, Shabala L. Ion transport and osmotic adjustment in plants and bacteria. BioMol Concepts. 2011;2(5):407-19. https://doi.org/10.1515/BMC.2 011.032 .
Shani E, Salehin M, Zhang Y, Sanchez SE, Doherty C, Wang R, et al. Plant stress tolerance requires auxin-sensitive Aux/IAA transcriptional repressors. Curr Biol. 2017;27(3):437-44. https://doi.org/10.1016/j.cub.2016.12.016.

Sharp RE, Poroyko V, Hejlek LG, Spollen WG, Springer GK, Bohnert HJ, et al. Root growth maintenance during water deficits: physiology to functional genomics. J Exp Bot. 2004;55(407):2343-51. https://doi.org/10.1093/jxb/erh276.

Shinozaki Y, Beauvoit BP, Takahara M, Hao S, Ezura K, Andrieu MH, et al. Fruit setting rewires central metabolism via gibberellin cascades. Proc Natl Acad Sci U S A. 2020;117(38):23970-81. https://doi.org/10.1073/pna s.2011859117.

Shohat H, Ceriker H, Vasuki H, Illouz-Eliaz N, Blum S, Amsellem Z, Tarkowska D, Aharoni A, Eshed Y, Weiss D. Inhibition of gibberellin accumulation by water deficiency promotes fast and long-term 'drought avoidance' responses in tomato. New Phytol. 2021;232:1985-98.

Shohat H, Illouz-Eliaz N, Kanno Y, Seo M, Weiss D. The tomato DELLA protein PROCERA promotes abscisic acid responses in guard cells by upregulating an abscisic acid transporter. Plant Physiol. 2020;184(1):518-28. https://doi.org/1 0.1104/pp.20.00485

Skirycz A, Inzé D. More from less: plant growth under limited water. Curr Opin Biotechnol. 2010;21(2):197-203. https://doi.org/10.1016/j.copbio.2010.03.002

Spielmeyer W, Ellis MH, Chandler PM. Semidwarf (sd-1), "green revolution" rice, contains a defective gibberellin 20-oxidase gene. Proc Natl Acad Sci U S A. 2002;99(13):9043-8. https://doi.org/10.1073/pnas.132266399.

Steinbrecher T, Leubner-Metzger G. The biomechanics of seed germination. J Exp Bot. 2017;68(4):765-83. https://doi.org/10.1093/jxb/erw428.

Sun X, Jones WT, Rikkerink EHA. GRAS proteins: the versatile roles of intrinsically disordered proteins in plant signalling. Biochem J. 2012;442(1):1-12. https:// doi.org/10.1042/BJ20111766.

Tardieu F. Educated big data to study sensitivity to drought. Nat Food. 2020; 1(11):669-70. https://doi.org/10.1038/s43016-020-00187-4.

Tardieu F, Simonneau T, Muller B. The physiological basis of drought tolerance in crop plants: a scenario-dependent probabilistic approach. Ann Rev Plant Biol. 2018;69(1):733-59. https://doi.org/10.1146/annurev-a rplant-042817-040218.

The Tomato Genome Consortium. The tomato genome sequence provides insights into fleshy fruit evolution. Nature. 2012;485(7400):635-41. https://doi. org/10.1038/nature11119.

To A, Valon C, Savino G, Guilleminot J, Devic M, Giraudat J, et al. A network of local and redundant gene regulation governs Arabidopsis seed maturation. Plant Cell. 2006;18(7):1642-51. https://doi.org/10.1105/tpc.105.039925.

Turner NC. Turgor maintenance by osmotic adjustment: 40 years of progress. J Exp Bot. 2018;69(13):3223-33. https://doi.org/10.1093/jxb/ery181.

Tyler L, Thomas SG, Hu J, Dill A, Alonso JM, Ecker JR, et al. DELLA proteins and gibberellin-regulated seed germination and floral development in Arabidopsis. Plant Physiol. 2004;135(2):1008-19. https://doi.org/10.1104/pp.1 04.039578 .

Van Tuinen A, Peters AHLJ, Kendrick RE, Zeevaart JAD, Koornneef M. Characterization of the procera mutant of tomato and the interaction of gibberellins with end-of-day far-red light treatments. Physiol Plant. 1999; 106(1):121-8. https://doi.org/10.1034/j.1399-3054.1999.106117.x.

Varbanova M, Yamaguchi S, Yang Y, McKelvey K, Hanada A, Borochov R, et al. Methylation of gibberellins by Arabidopsis GAMT1 and GAMT2. Plant Cell. 2007;19(1):32-45. https://doi.org/10.1105/tpc.106.044602.

Verma V, Ravindran P, Kumar PP. Plant hormone-mediated regulation of stress responses. BMC Plant Biol. 2016;16(1):1-10. https://doi.org/10.1186/s12870-01 6-0771-y.

Vinocur B, Altman A. Recent advances in engineering plant tolerance to abiotic stress: achievements and limitations. Curr Opin Biotechnol. 2005;16(2):123-32. https://doi.org/10.1016/j.copbio.2005.02.001.

Wu K, Wang S, Song W, Zhang J, Wang Y, Liu Q, et al. Enhanced sustainable green revolution yield via nitrogen-responsive chromatin modulation in rice. Science. 2020:367:eaaz2046.

Xie Z, Nolan T, Tang B, Zhang M, Li Z, Yin Y. The AP2/ERF transcription factor TINY modulates brassinosteroid-regulated plant growth and drought responses in Arabidopsis. Plant Cell. 2019;31(8):1788-806. https://doi.org/1 $0.1105 /$ tpc. 18.00918

Yamaguchi S. Gibberellin metabolism and its regulation. Annu Rev Plant Biol. 2008;59:225-51.

Yaxley JR, Ross JJ, Sherriff L, Reid JB. Gibberellin biosynthesis mutations and root development in pea. Plant Physiol. 2001;125(2):626-33. https://doi.org/10.11 04/pp.125.2.627. 
Ye H, Liu S, Tang B, Chen J, Xie Z, Nolan TM, et al. RD26 mediates crosstalk between drought and brassinosteroid signalling pathways. Nat Commun 2017;8(1):14573. https://doi.org/10.1038/ncomms 14573.

Yoshida H, Hirano K, Sato T, Mitsuda N, Nomoto M, Maeo K, et al. DELLA protein functions as a transcriptional activator through the DNA binding of the INDETERMINATE DOMAIN family proteins. Proc Natl Acad Sci U S A. 2014; 111(21):7861-6. https://doi.org/10.1073/pnas.1321669111.

Zawaski C, Busov VB. Roles of gibberellin catabolism and signaling in growth and physiological response to drought and short-day photoperiods in Populus trees. PLoS One. 2014;9(1):1-12. https://doi.org/10.1371/journal.pone.0086217.

Zentella R, Zhang ZL, Park M, Thomas SG, Endo A, Murase K, et al. Global analysis of della direct targets in early gibberellin signaling in Arabidopsis. Plant Cell. 2007;19(10):3037-57. https://doi.org/10.1105/tpc.107.054999.

Zhou R, Kong L, Wu Z, Rosenqvist E, Wang Y, Zhao L, et al. Physiological response of tomatoes at drought, heat and their combination followed by recovery. Physiol Plant. 2019;165(2):144-54. https://doi.org/10.1111/ppl.12764.

Zhu H, Li C, Gao C. Applications of CRISPR-Cas in agriculture and plant biotechnology. Nat Rev Mol Cell Biol. 2020;21(11):661-77. https://doi.org/10.1 038/s41580-020-00288-9.

Zhu JK. Abiotic stress signaling and responses in plants. Cell. 2016;167(2):313-24. https://doi.org/10.1016/j.cell.2016.08.029.

Zhu Y, Nomura T, Xu Y, Zhang Y, Peng Y, Mao B, et al. ELONGATED UPPERMOST INTERNODE encodes a cytochrome P450 monooxygenase that epoxidizes gibberellins in a novel deactivation reaction in rice. Plant Cell. 2006;18(2): 442-56. https://doi.org/10.1105/tpc.105.038455.

Zhu Z, Kang X, Lor VS, Weiss D, Olszewski N. Characterization of a semidominant dwarfing PROCERA allele identified in a screen for CRISPR/Cas9-induced suppressors of loss-of-function alleles. Plant Biotechnol J. 2019;17(2):319-21. https://doi.org/10.1111/pbi.13027.

\section{Publisher's Note}

Springer Nature remains neutral with regard to jurisdictional claims in published maps and institutional affiliations.

Ready to submit your research? Choose BMC and benefit from:

- fast, convenient online submission

- thorough peer review by experienced researchers in your field

- rapid publication on acceptance

- support for research data, including large and complex data types

- gold Open Access which fosters wider collaboration and increased citations

- maximum visibility for your research: over $100 \mathrm{M}$ website views per year

At $\mathrm{BMC}$, research is always in progress.

Learn more biomedcentral.com/submissions 